\title{
Rethinking Being Gricean: New Challenges for Metapragmatics ${ }^{1}$
}

\author{
Kasia M. Jaszczolt \\ University of Cambridge
}

\section{1. 'Being Gricean' and its challenges: An overview}

There is no doubt that 'being Gricean' has a fuzzy category membership. Depending on the level of generalization and the associated defining characteristics, one can find oneself inside or outside of such an abstract camp. In what follows, I address the question of what 'being Gricean' can, and should, mean, forty years on. The foundational influence of Paul Grice (1989) on contemporary pragmatic theory, in the Anglo-American tradition and beyond, has its roots in several core characteristics that in combination guaranteed its success. First, there is the focus on speaker intentions, or, to be more precise, a concept of a model speaker's intentions, in their role of explanantia for meaning in discourse. This he aptly combined with the rigidity of the truth-conditional method upon which his theory of communication is built. From the perspective of several decades, the defence of the truth-conditional method is sometimes considered as a weakness, in that implicatures were conceived of, so to speak, 'negatively', as theoretical constructs that 'save' the truth-conditional approach. This criticism pertains, albeit in a different way, to Grice's conceptualization of both conventional and conversational implicatures. However, future developments in the post-Gricean contextualist tradition (Sperber and Wilson 1986/95, 2012; Carston 1988, 2002; Recanati 1989, 2010; Jaszczolt 2005, 2016a) have demonstrated that truth conditions are still the most precise tool that linguists have at their disposal to theorize about meaning in a way that affords systematicity and predictive power. Another characteristic that ought to be listed here is his classification of the directions that interactants follow in deriving implied meanings that allows for the calculation and prediction of implicatures - a classification in the form of maxims of conversation. Again, although these have since been criticised for their lack of

\footnotetext{
${ }^{1}$ Research for this paper was partly supported by the Cambridge Humanities Research Grant Rethinking Being Gricean: New Challenges for Metapragmatics https://www.mml.cam.ac.uk/rethinking-being-gricean and was presented at the Pragmasophia 2 conference, Lisbon and the American Pragmatics Association conference, AMPRA 4, Albany NY. I am grateful to the audiences of these events, as well as to Chi-Hé Elder, Roberto B. Sileo, Michael Haugh, and two anonymous reviewers for their comments and suggestions.
} 
psychological plausibility and the lack of methodological rigidity, and have been pulled in different directions by neo-Griceans and Relevance theorists (Horn 1984, 1988; Levinson 1987, 2000; Sperber and Wilson 1986/95), a systematic account of conversational inference arguably remains Grice's main legacy. ${ }^{2}$ Next, when we combine these cornerstones with the philosophical foundations of meaning $\mathrm{N}_{\mathrm{N}}$ whereby the recognition of the speaker's intention and the associated hearer's belief about the speaker's meaning also become the necessary defining characteristics, it is easy to see how the legacy is discernible both in the psychology of utterance processing and in many formal, including computational, approaches to modelling meaning.

Arguably, forty years on, post-Gricean pragmatics is still the most successful and methodologically rigorous approach to utterance meaning. However, and perhaps as a corollary of its extensive development, it has become necessary to ask what 'being Gricean' means for its current advocates. In this paper I address this question with respect to the current Anglo-American, truth-conditional paradigm, asking specifically how much, and on what identifiable dimensions, one can depart from his program and still remain 'Gricean'. In the past four decades, 'being Gricean' used to be associated with a well-focused, fairly unidirectional inquiry into meaning. 'Post-Griceans' tended to question the plausibility of the semantics/pragmatics boundary that emerged from his delimitation of what is said (Grice 1978), progressing to questioning the need for semantic ambiguity in support of semantic underdetermination and the associated intrusion of pragmatic information into the truthconditional content (Atlas 1977, 1979, 1989; Kempson 1975, 1979, 1986; Wilson 1975; Sperber and Wilson 1986/95). But the state-of-the-art of 'being Gricean' appears to be very different. The term 'Gricean pragmatics' appears to have been diluted to such an extent that it is has become necessary to ask what criteria one ought to adopt to delimit this orientation.

The label has generated very different challenges on several dimensions. First, (i) the role of inferential meanings has been questioned in that communication has since often been envisaged as mostly direct and non-inferential (Recanati, e.g. 2004, 2016). In a similar spirit, (ii) the layered, also sometimes called 'pipeline' or 'imbricated' picture of meaning (Parikh 2010) has been questioned within situation and game-theoretic semantics (Lewis 1979; Barwise and Perry 1983), and recently in their offshoot Equilibrium Semantics (Parikh 2010). It has been argued that discourse meaning ought not to be analysed by breaking it down into

\footnotetext{
${ }^{2}$ Pace some remarks in the history of philosophy and in French linguistics suggesting an analogous concept to Grice's implicature (see e.g. Mill 1872 or Ducrot 1972). The credit for the influential systematization of these ideas still goes to Grice.
} 
the logical form (the output of syntactic processing), its expansions and completions (a.k.a. modulation, explicatures, or implicitures, depending on the framework ${ }^{3}$ ), and additional inferred meanings (implicatures), because in practice its recovery follows the principles of interaction or a language game in which the players simply strive for an equilibrium. The 'pipeline' picture has been put into question in a double way in that it does not suffice to demonstrate empirically that (ii.a) various processes of meaning recovery need not necessarily take place in a fixed order (which post-Griceans have already accomplished) but also (ii.b) the very classification of aspects of meaning $g_{N N}$ seems to be called into question. Next, (iii) the explanatory role of intentions has often been denied in an attempt to reinstate the idea of multiple semantic ambiguities in lieu of meaning underdetermination, with the aim of aiding computational, formalizable accounts of discourse meaning (e.g. Lepore and Stone 2015). This has reopened the question as to (iv) what kind of content, and how much of it, is attributable to grammar, following up on earlier proposals of the grammatical origin of some pragmatic meanings that were standardly classified as implicatures (Chierchia 2004; Chierchia et al. 2012). Along yet another dimension, (v) the focus on cooperative interaction and proposition-based theorizing has been replaced with a focus on non-cooperative, such as strategic, communication and dialogue as the associated object of analysis (e.g. Asher and Lascarides 2013). Finally, Grice's project was a project in philosophy of language and as such in philosophical pragmatics. Theoretical, introspection-based methods employed without recourse to experimental or other empirical inquiries are nowadays shunned in many pragmatics circles. So, the question arises regarding (vi) the place of philosophical pragmatics on a map of current research into meaning in communication.

In this context, a metapragmatic question arises as to what qualitative and associated quantitative criteria current pragmatic theory has to fulfil in order to count as Gricean pragmatics. In this paper I address this question by discussing the identified areas (i)-(vi). Further, in doing so, using these indicators, I attempt to address the question 'Quo vadis, pragmatics?' with respect to the post-Gricean tradition. My metatheoretic inquiry begins by critically discussing the dimensions on which the Gricean program has been challenged and proceeds to arguing that none of the challenges constitutes a real threat to it. I develop two strands of argumentation showing how the approaches either (a) can be incorporated as its extensions or (b) are in pursuit of different goals and as such are not in competition with it.

\footnotetext{
${ }^{3}$ The exact comparison between various suggested theoretical constructs will not interest us here. See e.g. Jaszczolt 2012 for an introduction.
} 
Argument (a) applies to automatic meaning assignment, the rejection of the 'pipeline' picture of meaning, emphasis on conventions, strategic conversation and generalized cognition.

Argument (b) applies to the revival of semantic ambiguity and the grammatical foundation of implicatures. It is therefore concluded that the Gricean program can be relaxed on the dimensions covered by (a) and co-exist with the approaches subscribing to (b).

\section{A metapragmatic journey}

The directions along which the Gricean program has been questioned, identified in Section 1, have roots that are at least cotemporaneous with Grice. But it is only relatively recently that 'non-Gricean communication' has been brought to the fore in this contrastive juxtaposition, either through emphasising the fact that cooperation cannot be taken for granted and, arguably a fortiori, that cooperative conversation is by no means the only kind of conversation worth investigating ${ }^{4}$, or by denying the adequacy of a proposition-based account of meaning. The directions in (i)-(vi) all revolve around these main challenges, one of which we can call teleological and the other structural. In other words, the aims of the interactants are diversified and do not always fit under the umbrella term of cooperation (the teleological challenge) and the conceptual structure does not always fit neatly with the proposition derived from the logical form of the uttered sentence; it may not even follow from it as its extension (the structural challenge).

In Section 3 I further discuss the six identified dimensions. Before that, however, it is necessary to explain what is meant here by a 'metapragmatic journey'. While 'metasemantics' is a relatively well established theoretical concept, 'metapragmatics' is still largely up for grabs. ${ }^{5}$ Metasemantics concerns itself with providing a theoretical framework

\footnotetext{
${ }^{4}$ See here e.g. Sperber and Wilson 1986/95 and Wilson and Sperber 2000 on the maxim of truthfulness; Saul 2012 on the search for the semantic framework for analysing lying and misleading; or Asher and Lascarides 2013 on strategic communication.

${ }^{5}$ Caffi (e.g. 1994/2006) distinguishes three senses of metapragmatics: (i) a theoretical inquiry into the object, scope and epistemological foundations of pragmatics; (ii) a study of the conditions facilitating the use of language in communication; and (iii) an inquiry into speakers' competence that testifies to their judgements of appropriateness in communicative behaviour. She also emphasises the distinction between metapragmatics and metacommunication where the latter concerns the effects of communication on the interactants (Caffi 1984). Sense (iii) has then been developed into a study of metapragmatic awareness and its indicators in the form of metapragmatic expressions (Caffi 2016). In this vein, according to Haugh (2018: 619), '[m] etapragmatics is concerned with the study of reflexive awareness on the part of participants in interaction, and observers of interactions, about the language that is being used in those interactions'. This definition, close to Caffi's (iii), allows him to explore the use of corpus-based methods for the investigation of metapragmatic terms. Haugh's definition is guided by the assumption that a theorist identifies and follows common practices in attempting to understand linguistic interaction - in other words, it works on the ethnomethodological assumptions. My use of the term is broader and more in line with Caffi's (i): it pertains to 'theories about pragmatic theories'. But it also reflects a rather fundamental difference in the judgement of the playing field: it is no longer the case that metasemantics is an obscure and neglected area (Caffi 1994/2006: 83). Metasemantics is now at a forefront of
} 
for the theory of linguistic meaning. As such, it addresses metatheoretic questions, questions belonging to philosophy of linguistics, such as what constitutes the object of study of the theory of meaning or what direction should be taken in addressing questions about meaning (see Soames 2014a). It is sometimes identified with the 'metaphysics of meaning' in that 'metasemantics is in the business of providing metaphysical explanations of semantic facts' (Burgess and Sherman 2014: 2). It addresses foundational questions concerning how linguistic structures and corresponding thoughts relate to the world. ${ }^{6}$ Analogously, metapragmatics concerns itself with 'metaphysics of communication' and with foundational questions about communication. When taken as part of the discipline of linguistics ${ }^{7}$, it becomes a metatheoretic inquiry into how linguistic communication relates to the world. In simpler terms, just as metasemantics theorizes about theories of meaning, so metapragmatics theorizes about theories of communication. It addresses the foundations of the study of language use. What follows is an inquiry into metapragmatics.

\section{Gricean pragmatics, quo vadis?}

\subsection{Questioning the 'pipeline' picture}

There is a relatively simple and methodical picture that arises from Grice's $(1975,1978)$ theory of meaning $g_{\mathrm{NN}}$ : there is what is said, the truth-conditional content of the sentence, pertaining to the output of syntactic processing, completed when necessary by the resolution of indexical terms and disambiguation. This component gives rise to an array of implicatures, some of which embellish it, and others stem out of the blatant need to deny it. Next, postGricean research moved the boundary of the truth-conditional content and allowed in more pragmatic aspects of meaning. It also questioned the order in which these components are accessed (e.g. Carston 2007). But the question addressed here is not where to place the boundary between semantics and pragmatics ${ }^{8}$ but rather whether this segmented, essentially syntax-based representation consisting of a logical form plus pragmatic enrichment or other amendments, plus implicatures offers the most adequate representation of meaning in communication in the first place. First of all, communication is often conceived of as direct,

inquiry in philosophy of language (see e.g. the contributions to Burgess and Sherman, eds, 2014). As such, it testifies against the Wittgensteinian (1953) scepticism, followed by Caffi (1994/2006), about the utility of foundational metadiscourse.

${ }^{6}$ For the discussion of the term see also Soames 2014a and other contributions to Burgess and Sherman (eds) 2014; Soames 2014b, c and Jaszczolt 2018. For an example of a metasemantic inquiry see Sainsbury 2014 and a response in Jaszczolt 2017.

${ }^{7}$ There is no consensus on this matter but we will take pragmatics to mean 'the study of human language use as it is exercised in a community of social practice' (Mey 2006: 51).

${ }^{8}$ See Jaszczolt 2012 for an overview. 
non-inferential. On this construal, a speaker's thought is essentially indexical, in the sense that in thinking one employs context-dependent and perspectival private modes of presentation, and is represented as such by the addressee. Presenting it as 'a thought expressed by an utterance' distorts the picture (Recanati 2016). By recognising this directness we would come close to a view where communication is seen as a series of interactively made decisions: a game where a speaker's choice of an utterance and the addressee's choice of the interpretation must reach an equilibrium: 'a balance among the choices and strategies available to the speaker and addressee in each game' (Parikh 2010: 26). Game theory, and as such interactive decision-making, has been applied to linguistic communication to focus on situations and the choices interlocutors make in them. ${ }^{9}$ In contrast, the Gricean picture appears as the assumed but somewhat counterintuitive 'pipeline' view (Parikh 2010: 123): underspecified semantic representations subjected (globally or locally, no matter) to pragmatic influences conform to the methodological principle 'to get as far as we can with just language by itself and bring in situations only when we fail to go all the way' (ibid.). The post-Gricean 'more imbricated picture of meaning' (Parikh 2010: 5) in the form of radical pragmatics comes a little closer to game-theoretic semantics but, according to Parikh, is not satisfactory precisely because it does not go the whole way towards blurring the boundaries between the components and aspects of utterance meaning in favour of situated speech actions (moves in a language game). On the other hand, game-theoretic semantics such as Parikh's (2010) Equilibrium Semantics comes first and permeates every level of linguistic communication, so to speak, as a matter of course, not merely as a special process of meaning adjustment. Explicit and implicit, locutionary and illocutionary meanings are treated equally and achieve equal status. And they are all in the domain of semantic analysis.

So, is there logical progression that might lead a Gricean towards a game-theoretic account without at any point entirely relinquishing the essence of 'being Gricean'? Let us first look at the object of study. Default Semantics (Jaszczolt 2005, 2010) professes to be a Gricean theory of communication in the sense that it founds the analysis of meaning in communication on speaker intentions and their recognition; it also concerns itself with the propositional content of the intended (and recovered) message and as such makes use of the truth-conditional method. At the same time, it takes acts of communication as its object in that the primary/secondary meaning distinction adopted there is orthogonal to the what is

\footnotetext{
${ }^{9}$ For seminal references see Lewis 1979; Barwise and Perry 1983; for an informative introduction to GameTheoretic Pragmatics see Franke 2013.
} 
said/what is implicated divide: if the message is delivered indirectly, it is the main, primary implicature that constitutes the primary meaning and it is this implicature that acquires the truth-conditional treatment. So, Default Semantics rejects the post-Gricean 'imbricated picture of meaning' but preserves the core Gricean assumptions concerning the provenance and type of meaning that constitutes the object of analysis: intended, recovered, based on general principles of rationality, formalizable, truth-conditional. It agrees with Equilibrium Semantics on the uniform treatment of explicit and implicit meaning (Parikh 2010: 162) in that, to repeat, the primary/secondary meaning distinction cuts across the said/implicit divide. For example, given the conversation in (1), both theories would take the meaning in (2b) rather than (2a) as their main object of analysis. Allowing for a given context, the bridging premise that in the United Kingdom it is illegal to sell alcohol to persons under 18 years old leads directly to the primary intended message in $(2 b)$.

(1) A: Can I have some champagne?

B: You are under 18.

(2a) A is under 18 years old.

(2b) A cannot have champagne.

This liberal construction of the primary meaning, which then becomes the object of truthconditional analysis, has already led to discussions as to whether Default Semantics is 'still Gricean'. ${ }^{10}$ Even if it belongs to the post-Gricean camp in view of the adopted order of explanation from intentions to meanings, it questions the utility of the cline within meaning $g_{N N}$ and opts for a conceptual representation that merges information arrived at through different interacting processes that is not constrained by the Gricean 'pipeline' picture. Next, although at present it remains uncommitted on the question of modularity (Jaszczolt 2016a), it has some affinity with approaches that question the modular approach to meaning and replace it with the view of language understanding as social cognition, founded on goals and actions, such as for example Goodman and Stuhlmüller (2013) and Goodman and Lassiter (2015), where general cognitive mechanisms are responsible for the recovery of implicatures. Finally, it is compatible with the empirical evidence for discerned patterns of activity that emphasise the role of conventions in decision making (Jaszczolt and Witek 2018). In short, it comes close to models utilising speech acts, conventions and social practices.

\footnotetext{
${ }^{10}$ See e.g. Atlas 2016 and Parikh 2016.
} 
One recent proposal of a non-Gricean outlook on communication that generated more discussion and controversy than the others is Lepore and Stone's (2015) Imagination and Convention: Distinguishing Grammar and Inference in Language. One of the least controversial claims there is probably that Grice's conversational implicature has been given too significant a role in utterance interpretation and part of its burden should legitimately go to conventions. One of the most controversial ones is subsuming conventions under the power of grammar and leaving pragmatics with the task of disambiguation. We have here the reopening of the old discussion of intentions vis-à-vis conventions known from Strawson and Searle, but now put in the new light of reopening the question of the power of grammar - a topic the importance of which I flag in the next section. According to Lepore and Stone, intentions should be avoided as an explanatory tool. There is powerful grammar that arguably sorts out anaphoric links, presuppositions, and indexicals. Then there are conventions that belong with the grammar, and finally there is the whole array of what they call 'imagination' - interpretations that follow the direction specific to the individual's thought and as such fall outside of the domain of theoretical linguistic inquiry; 'imaginative practices' are separate from meaning and grammar. Essentially, 'meaning is a matter of conventions' (p. 199): it is not up for grabs, it is 'grammatically specified' (p. 208). ${ }^{11}$

There are two ways to view this apparent contrast between Gricean and gametheoretic (or goal-, action-, convention-based) approaches. The first one is to contrast them in that the order of explanation appears to be opposite: from intentions to conventions and from conventions to intentions respectively. But there is a much more satisfactory way of assessing their compatibility, on which 'being Gricean' reveals itself to be a half-way point on the way to what we often take as the opposite order of explanation. In Speech Act Theory, the emphasis is on conventions and patterns. So, the order of explanation appears to be the opposite from that adopted by Griceans: speech acts explain speakers' intentions as it were rather than the other way round. And here is where Leezenberg's (2006) proposal fits in. Relying on the explanatory power of intentions encounters one serious danger, spelled out by Leezenberg (2006: 4-5) as follows:

'...Grice presupposes a strongly universalist (dare I say Kantian?) conception of rationality: given a specific situation, there seems to be just one optimally rational course of action, which is the same for all humans'.

\footnotetext{
${ }^{11}$ See also Jaszczolt's (2016b) review and Lepore and Stone's (2016) response.
} 
But at the same time, he points out that this is only part of the picture; it seems necessary to consider the foundations of such a view that can be traced to the European tradition in political philosophy, in particular Hobbes and Rousseau, and the idea of liberalism based on the rationality of adhering to a social contract which entails adhering to societal norms and conventions. In this light, what had appeared to be the opposite order of explanation appears to be the Gricean order but taken further, to its historical and logical limits. The question then arises whether one can go that far with Grice's universalism and deflate the explanatory role of intentions in favour of precisely these conventions and patterns from which his maxims arguably emerge. Looked at in this light, 'being Gricean' amounts to merely stopping partway, so to speak, acknowledging the role of conventions in generalized conversational implicatures but not beyond, short of embracing the true origin of his heuristics and, $a$ fortiori, short of embracing the explanatory role of conventions.

As a case study, Leezenberg contrasts here what he calls 'Confucian pragmatics' that relies on adhering to conventions ('rites') and Gricean pragmatics that, arguably, can ultimately be traced to conventions but does not make a methodological use of them: Grice proceeds from intentions to explaining linguistic behaviour, while Confucius, and closer to home ordinary language philosophers (Wittgenstein 1953; Austin 1962) proceed in the opposite direction. Perhaps it is with this reversal of the order of explanation that 'being Gricean' truly ends. And if so, then 'being Gricean' can be seen either (i.a) positively, couched in Kantian tradition, or, again (i.b) positively, as a philosophical prelude to a journey into psychologism as undertaken for instance by Relevance theory, or, less favourably, (ii) as stopping half-way before the explanation in terms of speech acts, social rules, laws and conventions is reached. Construal (i) amounts to a qualitative contrast, while (ii) to quantitative differences on a cline of explanatory tools: from intentions to conventions, or from rationality of behaviour to social rules. But taking this analysis further requires a separate, more extensive inquiry in metapragmatics. I shall now flag, very briefly, the remaining aspects on which 'being Gricean' is to be assessed.

\section{2. 'Put the blame on Mame, boys': The power of grammar}

According to Lepore and Stone (2015: 83), '[p]ragmatics can be, at most, a theory of disambiguation; pragmatic reasoning never contributes content to utterances'. They consider disambiguation to be the sole pragmatic process, defined as 'finding the right reading of the utterance, understood as a grammatically specified pairing of form and meaning' (p. 88). 
Some of the proposed domains in which the explanation has shifted away from pragmatics are well justified in principle. For example, scalar implicatures are viewed there as effects of information structure. But, on the other hand, information structure is understood as an epiphenomenon of grammar, which is much more contentious than its construal in the cognate theory of Segmented Discourse Representation (SDRT, Asher and Lascarides 2003) where the 'logic of information packaging' (the logic using nonmonotonic inference) and its metalanguage they call 'glue logic' (accounting for the rhetorical relations between propositions) are separate from the content, represented in a separate metalanguage ('logic of information content'). In other words, the pragmatic rules and the grammar are kept suitably distinct. In other words again, when we put theories of presupposition, indexicals and anaphora resolution, or scalar implicature, in the domain of information structure, this can be understood either (i) as being caused directly by the grammar, as in Lepore and Stone or Chierchia $(2004,2012)$, or (ii) as the effect of the 'middle' system of discourse structure that affords its own metalanguage and rules, as in SDRT. Needless to say, it is the first that requires a greater leap of faith: discourse rules have to be fitted into the grammar bottom-up, starting with the language system itself.

For scalar implicature, Chierchia (2004) defends the following view. Grammar contains 'interpretive procedures' that result in two different values of expressions: the ordinary value and the one strengthened by the upper bound. So, 'implicatures, like core meaning, are computed compositionally bottom-up, off LF structures' (Chierchia 2004: 64). Grammatical conditions, such as downward-entailing contexts, provide the necessary constraints. So, scalars are not, pace Grice, wholly pragmatic. But we have to remember that not all scalars are alike. Some of them cannot be attributed to the interpretive procedures of grammar as readily as others - ad hoc scales being at the very end of such a spectrum as entirely context-dependent, purpose-made sets of alternatives. Even among typical, generalized-implicature scalars, some expressions give rise to upper-bounded readings more easily than others (Tiel et al 2016). So, the attempted takeover by grammar is not as threatening to the Gricean program as it may appear to be: some scalars may be generated by grammar, but then the utility of the theory has to be limited just to this category - and even within the category the generalization has to allow for vagaries of interpretation. In a similar vein, Stanley and Szabó's (2000) proposal of a grammatical trigger of quantifier domain restriction, where a common noun 'co-habits' the $\mathrm{N}$ node with the contextually salient restriction, is an attempt at a structure-based explanation of a kind of meaning that is essentially purely context-driven. 
Presupposition and anaphora are other areas where the debate over the role of grammar still continues but this topic will have to be left for another occasion. Suffice it to say that solutions to discourse anaphora seem to pull it in different directions. For example, the presupposition as anaphora view advocates going back along the projection line in search of an antecedent and if a suitable one is not found, accommodating, making use of pragmatic factors that contribute to the preference order (van der Sandt 1992, 2012), while Lepore and Stone (2015: 124-125), following the tradition in attention theory (see e.g. Grosz et al. 1995 and Kehler 2002 for a discussion), advocate the priority of binding to subject in that the subject position is, according to them, associated with higher prominence and as such acquires by convention the dedicated role of an antecedent in anaphoric links. In view of the lack of empirical support, and emerging support to the contrary, their claim fails to stand. ${ }^{12}$ Grammar is also deemed responsible for differences in reading between cases of sentential conjunction, where, according to Lepore and Stone, the Simple Past tense form in (3a) triggers the temporal sequence interpretation by (grammatical) convention, while the Present Perfect counterpart in (3b) lacks this interpretation.

(3a) Oil prices doubled and demand for consumer goods plunged.

(3b) Oil prices have doubled and demand for consumer goods has plunged.

(from Lepore and Stone 2015: 23, 117). ${ }^{13}$ As they say (p. 119), 'with tense (..), understanding involves choosing the reading that makes the most sense from the candidates delivered by the grammar.' 14

Empirical research conducted within my ongoing project supports the presupposition as anaphora view but not the default binding to subject. Instead, it supports a strong contextual effect from biasing situations. ${ }^{15}$ What matters for our current purpose is that the attempts to trace the discourse-anaphoric link to grammar are not strongly supported. Even if there is a default dependence, the fact that biasing context can override it means that the form-meaning association is not on a par with the meaning generated by the lexicon or

\footnotetext{
${ }^{12}$ See Sileo and Jaszczolt forthcoming for empirical evidence that their example (i) (Lepore and Stone 2015: 124) does not generalize.

(i) The President nominated Jones. He expected a quick confirmation.

${ }^{13}$ My thanks go to Roberto B. Sileo for drawing my attention to these examples. For empirical evidence against the grammatical explanation of conjunction see Jaszczolt and Sileo in progress.

${ }^{14}$ My emphasis.

15 'Rethinking being Gricean'. See references in fn *, 12 and 13.
} 
grammar and as such deserves its separate level of analysis - à la Gricean pragmatics or SDRT. Mutatis mutandis, the same argument pertains to scalar implicatures.

At the same time, when Lepore and Stone (2015: 117) claim that Grice's derivation of the temporal meaning of and 'hides a covert appeal to a convention', we are reminded of Leezenberg's pursuit of Grice's derivation all the way to its alleged origin in conventions. So, although the appeal to grammar may prove to have gone one step too far, the explanatory role of conventions seems to be at least compatible with both views. And, to repeat, if conventions are to acquire the role of an explanans, we have to decide whether this reverses the order of explanation or merely takes intention-based generalizations to their natural end.

In the context of the discussion of the criteria delineating 'being Gricean', it appears that carving off some of the phenomena and allocating them to grammar poses no real threat. What is concerning, however, is how they are allocated to grammar. In Lepore and Stone's account, the middle level of cross-sentential discourse relations becomes allocated to grammar, so to speak, by fiat. Next, grammar is assumed to produce multiple, alternative interpretations. While this outlook may be advantageous for computational modelling of discourse, and as such for, say, distributional, vector semantics (see Jurafsky and Martin $2009,2016)$, the difference is that it doesn't aim at the psychological plausibility that is so indispensable in an account of communication. A fortiori, a reductive explanation provided by psychologism is not a methodological option. Psychologism may be rightfully exorcised from accounts of language systems, but when we theorize about language use, it becomes a methodologically viable, and tempting, form of reductionism. On the other hand, on Lepore and Stone's division of the field, grammar becomes overly powerful - 'blamed', so to speak, for a wide range of ambiguities. It leaves pragmatics with the modest role of disambiguating and exorcising all that doesn't fit - metaphors and any form of non-literality - to the extralinguistic domain of private thoughts and 'imaginings'. But 'blaming it all on grammar' simply will not do - grammar is a property of the language system, and syntactic analysis is a tool that is rightfully supposed to take us only part-way towards speaker meaning. Invoking multiple meanings and ascribing them to grammar runs the risk of confusing an analysis on the level of language system with an analysis of communication. Grammar becomes a femme fatale, Mame from the song sung by Rita Hayworth ${ }^{16}$ in Gilda whom one can blame for all the world's disasters - the earthquake in San Francisco, shooting in Klondike, misplaced meaning, and all.

\footnotetext{
${ }^{16}$ Strictly speaking, dubbed by Anita Ellis.
} 


\subsection{The uncooperative principle?}

Game-theoretic approaches have another important weakening effect on the Gricean principles in that they foreground the fact that not all communication is cooperative. There are standard scenarios and standard settings in which implicatures do not appear to conform to Gricean maxims, neo-Gricean principles or heuristics, or the principles of Relevance. Such scenarios are quite fixed and limited: courtroom interaction, teacher-pupil interaction, haggling over the price of goods, or political discussion. We can add to this any conversation that proceeds on the assumption of the lack of cooperation, for some reason or other - for example to avoid punishment or blame, to protect someone's reputation or right to privacy, to ensure the confidentiality of a piece of information, or to prevent distress. Gricean and postGricean accounts tend to marginalise these scenarios, while game-theoretic accounts that foreground speech actions, conventions, and the 'equilibrium-seeking' conversational behaviour stress their significance: 'people often communicate in the context of diverging interests' (Asher and Lascarides 2013: 11). The question that arises for the purpose of this discussion is whether they pose a threat to the Gricean way of explaining conversation. Asher and Lascarides view Gricean cooperative interaction as a subset of cases; they derive its explanation from game-theoretic principles. ${ }^{17}$ The core question is of course whether these scenarios are truly cases of non-Gricean communication or merely cases where the speaker has good reasons to lie, mislead, hide the truth, and so forth and these reasons are perfectly explicable within the Gricean framework on some level of sub-intentions. But if, for the sake of the argument, we consider them to be non-Gricean, the answer to the threat question may depend on the choice of one of the two directions discussed in Section 3.1: either we rest with the claim that Gricean principles and principles of ordinary language philosophy including Speech Act Theory employ opposite orders of explanation as far as the 'intention $\leftrightarrow$ meaning' relation is concerned, or we go along with Leezenberg's view that Grice stops half-

\footnotetext{
17 ،...we have derived Gricean cooperativity from a more general game-theoretic axiomatization of human behaviour that also handles non-cooperative conversation. ... we have replaced Gricean derivations of implicatures based on shared intentions with a different picture in which discourse coherence and its attendant implicatures emerge as a rational preference.' Asher and Lascarides (2013: 49). The question arises here as to whether their understanding of cooperation is the same as Grice's or perhaps is dictated by goals rather than the recovery of beliefs and intentions. Many thanks to Chi-Hé Elder for pointing this out to me. Moreover, as one referee points out, 'shared intentions' are too strong a condition to attribute to Grice's account of communication. A more appropriate understanding of the explanatory role of intentions in Grice's account is to refer to a concept of a model speaker's intentions, as I have done in Section 1 and in my theory of Default Semantics. An alternative route would be to weaken the condition as it was subsequently proposed in Relevance theory. I am flagging these important questions here and will leave them for a separate discussion.
} 
way towards the explanation, i.e. does not go as far as societal norms that underlie human rational behaviour and its principles. The choice is, to a large extent, methodological: it is a matter of what one wants to emphasise in theoretical explanations and how far it is reasonable to proceed. After all, one can take the explanatory dependency even further, from societal norms to biological laws, and then even to quantum theory, but these are much less likely to be considered as the possible limits of the Gricean thought! Methodological reductionism cannot be unprincipled.

\subsection{The future of philosophical pragmatics}

Paul Grice was a philosopher. He was interested in generalizations over human cooperative conversation and tried to put them into a format that allowed for making predictions. He also put them in a format that facilitated the formalization of pragmatics. ${ }^{18} \mathrm{He}$ was committed to the truth-conditional method of analysing meaning as the most precise and powerful way of approaching the vagaries of structures and the lexicon, on the foundation of which he built his model of speaker meaning. Finally, he was committed to intentions as an explanatory tool. But he was not committed to a distinction between linguistic and non-linguistic 'utterances', neither was he interested in linguistic or behavioural data beyond introspection and commonsense exemplification of the rationality of human conversational behaviour. When his views were taken up by linguists interested in utterance processing and linguists pursuing corpus or experimental pragmatics, this created a danger of teleological mismatches. Quite often in 'proving Grice wrong' they run the risk of talking at cross purposes: Grice's generalized implicatures do not become any less valuable generalizations when they are shown to be triggered by default in some contexts but not others or when they are shown not to be quick to process. His conventional implicatures do not become any less indispensable in his own model when they are argued to contribute to truth-conditional content: they were merely an answer to the problem with an imperfect metalanguage. Grice's program in philosophical pragmatics has to be taken as a self-contained entity and only used as an inspiration for exercises that differ in desiderata and methods.

In his 'Pragmatics in the history of linguistic thought', Andreas Jucker (2012: 512) predicts 'a continuing and perhaps accelerating diversification of approaches within pragmatics', also stressing the impact of computer-mediated communication on the goals and

\footnotetext{
${ }^{18}$ See e.g. Optimality Theory Pragmatics (Blutner and Zeevat 2004) that utilises Grice's maxims or neo-Gricean principles and heuristics in formulating constraints.
} 
directions, and of corpus pragmatics on the methods. These predictions are already coming true. But, arguably, they do not diminish the need for philosophical pragmatics à la Grice. By 'philosophical pragmatics' I mean here not only the traditional methods used in philosophy to address questions about meaning in conversation but more generally, as I extensively explain elsewhere, 'theoretical pragmatics (P) viewed as a branch of philosophy of language (PL) that concerns itself with meaning in natural language discourse and its relation to the mind and the world' (Jaszczolt 2018: 136) - pragmaticspPL. In spite of significant advances in neuroscience, we still know relatively little about how meaning is represented in the mind and how the process of meaning recovery proceeds. There are formal representations in semantics and pragmatics, on both sides of the Gricean/non-Gricean divide, that aspire to the status of mental representations. But there is no doubt that the debate itself belongs to the domain of philosophical pragmatics understood as pragmaticspPL ${ }^{19}$. A fortiori, there is no doubt that philosophical pragmatics will continue to occupy an important place, undiminished by the widening choice of methods. After all, metapragmatics concerns itself with pragmaticsPPL and only indirectly with methods such as theoretical argumentation, introspection, experimentation, corpus-study and so forth.

\section{Conclusions}

The question we have been pursuing here is: What exactly does one have to share with Grice to belong, in 2019, to what can be broadly called a Gricean paradigm in pragmatics? One definitely has to acknowledge the explanatory role of intentions, but these could arguably be taken as a route to social practices or conventions. And it appears that in spite of the advances of accounts that pack implicatures into grammar, intentions and conventions (as distinct from grammar) are still thriving as explanatory tools. ${ }^{20}$ One also has to adopt the truth-conditional method of analysing meaning in that the entire Gricean program is built on the premise of 'saving' truth-conditional semantics by adding a pragmatic remedy. But, arguably, the extent and quality of the object analysed in this way can remain variable. The weakening of the appeal of the 'pipeline' picture is not a threat to the Gricean explanation of meaning: the object of study can be construed in a variety of ways while retaining intentions as an

\footnotetext{
${ }^{19}$ This qualification is necessary as the term 'philosophical pragmatics' is used in a variety of ways, for example as subsumed under philosophical logic or as subsumed under linguistic philosophy. See Jaszczolt 2018 for a discussion.

${ }^{20}$ To give a couple of recent examples, see 'Understanding intentions behind the referential/attributive distinction' (Henricks Stotts 2017) and, in a more unusual domain, an implicature-based account of the imperfective paradox in Vidal and Perrin 2017 where inference from the situation is responsible for the terminative or non-terminative reading of the progressive form.
} 
explanans and the truth-conditional method - the Default Semantics briefly discussed in Section 3.1 is an example of such an approach. Next, the revived grammar-pragmatics tug of war seems to result in a draw: some phenomena pragmaticised by Grice and grammaticised by computational linguists and formal semanticists seem to be best placed in the domain of discourse rules and conventions. Concerning the methods, pragmatics appears to give room both to empirical and philosophical (Gricean) inquiry: the first to firmly ground the generalization about language use through the research on corpora or through experimentation, and the latter to form initial hypothesis to be tested and, post-empirically, to launch theories that go beyond data-based generalizations. In other words, from the metapragmatic perspective, experimental and corpus pragmatics appear not as substitutes for philosophical pragmatics but as its methodological aids: the raison d'être of pragmaticspPL is not traditional argumentation and introspection but the identification of explanantia (ways to answer questions, explain phenomena, methods) and explananda (phenomena to be explained, questions and objectives). As such, it answers to metapragmatics, while methods in pragmatics, in turn, answer to pragmaticspPL.

Needless to say, although this brief discussion provides some foundations for addressing the question 'Quo vadis, pragmatics?', taking it further to future predictions would have to be an exercise in informed speculation. But the picture that emerges from this discussion testifies to (a) the possibility of blending of convention- and intention-based accounts, (b) the progressing awareness of the limitations of the 'pipeline' picture of meaning, as well as (c) the increasing foregrounding of non-cooperative communication. In this context, it also seems very likely that the main object of study may in the future follow the goal-theoretic, speech-act-based rather than Gricean, grammar-based directives. However, although Gricean pragmatics emerges from this inquiry as a view that is in principle more compatible with various other ways of construing meaning than a cursory glance at them would suggest, at this point 'being Gricean' seems to cease to fulfil its raison d'être. Including (the theoretical construct of) speaker's intentions as an explanans when conversational behaviour cannot be pegged on conventions or social rules, and following the truth-conditional method applied to a proposition that may pertain to an indirectly expressed thought, are justifiable characteristics of a pragmatic theory and, as we argued, are perfectly compatible with the Gricean direction of theorizing, but, paradoxically, they don't result in 'being Gricean': they result in a more adequate account of meaning in communication tout court. My tentative prediction is that, following a natural and positive stage of pluralism with respect to theoretical assumptions, concepts and explanations, pragmatic theory will cease to 
employ labels such as 'game theory, 'Speech Act Theory', or 'Gricean pragmatics' and emerge from the fragmentation of the pre-paradigmatic stage ${ }^{21}$ to form a paradigm in the science of communication, as a branch of social sciences.

\section{References}

Asher, N. and A. Lascarides. 2003. Logics of Conversation. Cambridge: Cambridge University Press.

Asher, N. and A. Lascarides. 2013. 'Strategic conversation'. Semantics \& Pragmatics 6. 1-62.

Atlas, J. D. 1977. 'Negation, ambiguity, and presupposition'. Linguistics and Philosophy 1. 321-336.

Atlas, J. D. 1979. 'How linguistics matters to philosophy: Presupposition, truth, and meaning'. In: C.-K. Oh and D.A. Dinneen (eds). 1979. Syntax and Semantics. Vol. 11. New York: Academic Press. 265-281.

Atlas, J. D. 1989. Philosophy Without Ambiguity: A Logico-Linguistic Essay. Oxford: Clarendon Press.

Atlas, J. D. 2016. 'Comments on K. Jaszczolt's Meaning in Linguistic Interaction:

Semantics, Metasemantics, Philosophy of Language'. Book Symposium on K. M. Jaszczolt Meaning in Linguistic Interaction, American Philosophical Association Pacific Division Meeting, San Francisco.

https://www.academia.edu/24318477/J._D._Atlas_Comments_on_K._Jaszczolts_Meaning_in_Linguist ic_Interaction_APA_Pacific_San_Francisco_2016_[accessed 19 June 2018].

Austin, J. L. 1962. How to Do Things with Words. Oxford: Clarendon Press.

Barwise, J. and J. Perry. 1983. Situations and Attitudes. Cambridge, MA: MIT Press.

Blutner, R and H. Zeevat (eds). 2004. Optimality Theory and Pragmatics.

Basingstoke: Palgrave Macmillan.

Burgess, A. and B. Sherman. 2014. 'Introduction: A plea for the metaphysics of meaning'. In:

A. Burgess and B. Sherman (eds). 2014. Metasemantics: New Essays on the Foundations of Meaning. Oxford: Oxford University Press. 1-16.

Burgess, A. and B. Sherman (eds). 2014. Metasemantics: New Essays on the

Foundations of Meaning. Oxford: Oxford University Press.

${ }^{21}$ Kuhn 1962. See also Jaszczolt 2018 on 'constructively eclectic paradigms' in metapragmatics. 
Caffi, C. 1984. 'Some remarks on illocution and metacommunication'. Journal of Pragmatics 8. 449-467.

Caffi, C. 1994. 'Metapragmatics'. In: R. E. Asher (ed.) Encyclopedia of Language and Linguistics. Oxford: Pergamon Press. 2461-2466. Revised edition reprinted in: K. Brown (ed.). 2006. Encyclopedia of Language and Linguistics. Second edition. Oxford: Elsevier. 8288.

Caffi, C. 2016. 'Revisiting metapragmatics: "What are we talking about?"'. In: K. Allan, A. Capone and I. Kecskes (eds). Pragmemes and Theories of Language Use. Dordrecht: Springer. 799-821.

Carston, R. 1988. 'Implicature, explicature, and truth-theoretic semantics'. In: R. M. Kempson (ed.). Mental Representations: The Interface Between Language and Reality. Cambridge: Cambridge University Press. 155-181.

Carston, R. 2002. Thoughts and Utterances: The Pragmatics of Explicit Communication. Oxford: Blackwell.

Carston, R. 2007. 'How many pragmatic systems are there?'. In: M. J. Frápolli (ed.). Saying, Meaning and Referring: Essays on François Recanati's Philosophy of Language. Basingstoke: Palgrave Macmillan. 18-48.

Chierchia, G. 2004. 'Scalar implicatures, polarity phenomena, and the syntax/ pragmatics interface'. In: A. Belletti (ed.). Structures and Beyond: The Cartography of Syntactic Structures, vol. 3. Oxford: Oxford University Press. 39-103.

Chierchia, G., D. Fox and B Spector. 2012. 'Scalar implicature as a grammatical phenomenon'. In: C. Maienborn, K. von Heusinger and P. Portner (eds). Semantics: An International Handbook of Natural Language Meaning, vol. 3. Berlin: de Gruyter Mouton. 2297-2331.

Ducrot, O. 1972. Dire et ne pas dire. Paris: Hermann.

Franke, M. 2013. 'Game Theoretic Pragmatics'. Philosophy Compass 8. 269-284.

Goodman, N. D. and D. Lassiter. 2015. 'Probabilistic semantics and pragmatics: Uncertainty in language and thought'. In: S. Lappin and C. Fox (eds). The Handbook of Contemporary Semantic Theory. Oxford: Wiley Blackwell. 655-686.

Goodman, N. and A. Stuhlmüller. 2013. 'Knowledge and implicature: Modeling language understanding as social cognition'. Topics in Cognitive Science 5. 173-184.

Grice, H. P. 1975. 'Logic and conversation'. In: P. Cole and J. L. Morgan (eds). Syntax and Semantics. Vol. 3. New York: Academic Press. Reprinted in: H. P. Grice. 1989. Studies in the Way of Words. Cambridge, Mass.: Harvard 
University Press. 22-40.

Grice, H. P. 1978. 'Further notes on logic and conversation'. In: P. Cole (ed.). Syntax and Semantics. Vol. 9. New York: Academic Press. Reprinted in: H. P. Grice. 1989. Studies in the Way of Words. Cambridge, MA: Harvard University Press. 41-57.

Grice, H. P. 1989. Studies in the Way of Words. Cambridge, MA: Harvard University Press.

Grosz, B. J., A. K. Joshi and S. Weinstein. 1995. 'Centering: A framework for modelling the local coherence of discourse'. Computational Linguistics 21. 203-225.

Haugh, M. 2018. 'Corpus-based metapragmatics'. In: A. Jucker, K. P. Schneider and W. Bublitz (eds). Methods in Pragmatics. Berlin: De Gruyter Mouton. 619-643.

Hendricks Stotts, M. 2017. 'Understanding the intentions behind the referential/attributive distinction'. Erkenntnis 82. 351-362.

Horn, L. R. 1984. 'Toward a new taxonomy for pragmatic inference: Q-based and R-based implicature'. In: Georgetown University Round Table on Languages and Linguistics 1984. Ed. By D. Schffrin. Washington, D.C.: Georgetown University Press. 11-42.

Horn, L. R. 1988. 'Pragmatic theory'. In: F. J. Newmeyer (ed.). Linguistics: the Cambridge Survey. Vol. 1. Cambridge: Cambridge University Press. 113-145.

Jaszczolt, K. M. 2005. Default Semantics: Foundations of a Compositional Theory of Acts of Communication. Oxford: Oxford University Press.

Jaszczolt, K. M. 2010. 'Default Semantics'. In: B. Heine and H. Narrog (eds.) The Oxford Handbook of Linguistic Analysis. Oxford: Oxford University Press. 215-246.

Jaszczolt, K. M. 2012. 'Semantics/pragmatics boundary disputes'. In: C. Maienborn, K. von Heusinger and P. Portner (eds). Semantics: An International Handbook of Natural Language Meaning. Vol. 3. Berlin: Mouton de Gruyter. 2333-2360.

Jaszczolt, K. M. 2016a. Meaning in Linguistic Interaction: Semantics, Metasemantics, Philosophy of Language. Oxford: Oxford University Press.

Jaszczolt, K. M. 2016b. 'On unimaginative imagination and conventional conventions: Response to Lepore and Stone'. Polish Journal of Philosophy 10. 89-98.

Jaszczolt, K. M. 2017. 'Slippery meaning and accountability'. In: F. Poggi and A. Capone (eds). Pragmatics and Law: Practical and Theoretical Perspectives. Dordrecht: Springer. 3-22.

Jaszczolt, K. M. 2018. 'Pragmatics and philosophy: In search of a paradigm'. Intercultural Pragmatics 15. 131-159.

Jaszczolt, K. M. and R. B. Sileo. In progress. 'Pragmatics and grammar as sources of 
temporal ordering in discourse'.

Jaszczolt, K. M. and M. Witek. 2018. 'Expressing the self: From types of de se to speech-act types'. In: M. Huang and K. M. Jaszczolt (eds). Expressing the Self: Cultural Diversity and Cognitive Universals. Oxford: Oxford University Press. 187222.

Jucker, A. H. 2012. 'Pragmatics in the history of linguistic thought'. In: K. Allan and K. M. Jaszczolt (eds). The Cambridge Handbook of Pragmatics. Cambridge: Cambridge University Press. 495-512.

Jurafsky, D. and J. H. Martin. 2009. Speech and Language Processing. London: Pearson Education.

Jurafsky, D. and J. H. Martin. 2016. 'Vector Semantics', for Speech and Language Processing (in progress), third edition, draft of November 7, 2016.

Kehler, A. 2002. Coherence, Reference, and the Theory of Grammar. Stanford: CSLI.

Kempson, R. M. 1975. Presupposition and the Delimitation of Semantics. Cambridge: Cambridge University Press.

Kempson, R. M. 1979. 'Presupposition, opacity, and ambiguity'. In: C.-K. Oh and D.A. Dinneen (eds). 1979. Syntax and Semantics. Vol. 11. New York: Academic Press. 283-297.

Kempson, R. M. 1986. ‘Ambiguity and the semantics-pragmatics distinction'. In: C. Travis (ed.). 1986. Meaning and Interpretation. Oxford: B. Blackwell. 77-103.

Kuhn, T. S. 1962. The Structure of Scientific Revolutions. Chicago: Chicago University Press. Leezenberg, M. 2006. 'Gricean and Confucian pragmatics: A contrastive analysis'. Journal of Foreign Languages 6. 2-21.

Lepore, E. and M. Stone. 2015. Imagination and Convention: Distinguishing Grammar And Inference in Language. Oxford: Oxford University Press.

Lepore, M. and M. Stone. 2016. 'Problems and perspectives on the limits of pragmatics: Reply to critics'. Polish Journal of Philosophy 10. 117-126.

Levinson, S. C. 1987. 'Minimization and conversational inference'. In: J. Verschueren and M. Bertuccelli-Papi (eds). The Pragmatic Perspective. Selected Papers from the 1985 International Pragmatics Conference. Amsterdam: J. Benjamins. 61-129.

Levinson, S. C. 2000. Presumptive Meanings: The Theory of Generalized Conversational Implicature. Cambridge, MA: MIT Press.

Lewis, D. 1979. 'Scorekeeping in a language game'. Journal of Philosophical Logic 
8. 339-359.

Mey, J. L. 2006. 'Pragmatics: Overview'. In: K. Brown (ed.) Encyclopedia of Language and Linguistics. Second edition. Oxford: Elsevier. 51-62.

Mill, J. S. 1872. The Examination of Sir William Hamilton's Philosophy. London: Longmans, Green, Reader \& Dyer. Fourth edition.

Parikh, P. 2010. Language and Equilibrium. Cambridge MA: MIT Press.

Parikh, P. 2016. 'Comments on Meaning in Linguistic Interaction'. Book Symposium on K. M. Jaszczolt, Meaning in Linguistic Interaction, American Philosophical Association Pacific Division Meeting, San Francisco.

https://www.academia.edu/24318355/P. Parikh_Comments_on_K. Jaszczolts_Meaning_in_Linguistic_Interact ion_APA_Pacific_San_Francisco_2016_[accessed 19 June 2018]

Recanati, F.1989. 'The pragmatics of what is said'. Mind and Language 4. Reprinted in: S. Davis (ed.). 1991. Pragmatics: A Reader. Oxford: Oxford University Press. 97-120.

Recanati, F. 2004. Literal Meaning. Cambridge: Cambridge University Press.

Recanati, F. 2010. Truth-Conditional Pragmatics. Oxford: Clarendon Press.

Recanati, F. 2016. 'Indexical thought: The communication problem'. In: M. GarcíaCarpintero and S. Torre (eds). About Oneself: De Se Thought and Communication. Oxford: Oxford University Press. 141-178.

Sainsbury, M. 2014. 'Fishy business'. Analysis 74. 3-5.

van der Sandt, R. 1992. 'Presupposition projection as anaphora resolution'. Journal of Semantics 9. 333-377.

van der Sandt, R. 2012. 'Presupposition and accommodation in discourse'. In: K.

Allan and K. M. Jaszczolt (eds). The Cambridge Handbook of Pragmatics. Cambridge: Cambridge University Press. 329-350.

Saul, J. M. 2012. Lying, Misleading, and What Is Said: An Exploration in Philosophy of Language and in Ethics. Oxford: Oxford University Press.

Sileo, R. B. and K. M. Jaszczolt. Forthcoming. 'Cross-sentential anaphora and the grammar/pragmatics distinction'.

Soames, S. 2014a. Preface to A. Burgess and B. Sherman (eds). Metasemantics: New Essays on the Foundations of Meaning. Oxford: Oxford University Press. v-viii.

Soames, S. 2014b. 'Cognitive propositions'. In: J. C. King, S. Soames, and J. Speaks. New Thinking about Propositions. Oxford: Oxford University Press. 91-124.

Soames, S. 2014c. 'Clarifying and improving the cognitive theory'. In: J. C. King, S. 
Soames, and J. Speaks. New Thinking about Propositions. Oxford: Oxford University Press. 226-244.

Sperber, D. and D. Wilson. 1986. Relevance: Communication and Cognition. Oxford:

Blackwell. Second edition 1995.

Sperber, D. and D. Wilson (eds). 2012. Meaning and Relevance. Cambridge: Cambridge University Press.

Stanley, J. and Z. G. Szabó. 2000. 'On quantifier domain restriction'. Mind and Language 15. 219-261.

van Tiel, B., E. van Miltenburg, N. Zevakhina, and B. Geurts. 2016. 'Scalar diversity'. Journal of Semantics 33. 137-175.

Vidal, M. and D. Perrin. 2017. 'A default-free solution to the imperfective paradox'. Synthese, published online 28 June 2017. DOI 10.1007/s11229-017-1474-0.

Wilson, D. 1975. Presuppositions and Non-Truth-Conditional Semantics. London: Academic Press.

Wittgenstein, L. 1953. Philosophische Untersuchungen /Philosophical Investigations. Oxford: Blackwell. Reprinted in 1958. Second edition. 